\title{
Study on the Thermal Environment and Indoor Comfort of Half Glass Curtain Buildings - a Case of Kouhu Visitor Center in Yunlin County, Taiwan
}

\author{
Ta-Ching Liang ${ }^{1}$ and Szu-Hsien Peng ${ }^{2}$ \\ ${ }^{1}$ Department of Leisure and Recreation, National Formosa University, Yunlin 632, Taiwan, R. O.C. \\ ${ }^{2}$ Department of Spatial Design, Chienkuo Technology University, Changhua 500, Taiwan, R.O.C.
}

\begin{abstract}
Located in the subtropics, the high temperature in summer affects indoor living environments in Taiwan. The use of perspective glass material for modern public buildings increases the transparency of landscape views; however, the solar radiation heat also increases the heat in indoor environment. In particular, visitor centers which offer service functions for large quantities of visitors should satisfy the demands for indoor environment comfort and energy saving. "Numerical simulation" and "field data" are therefore utilized in this study for mutual comparison and the analyses of duration of sunshine, temperature distribution, heat balance, and space comfort. The research result reveals that different building envelope materials, with distinct thermal resistance and thermal conductivity coefficients, as well as sunshine direction and duration, affect the heat transmitting indoors, change the indoor temperature and further influence the comfort of the indoor environment. In the future indoor venue comfort will affect visitors' recreational behaviours.
\end{abstract}

\section{Introduction}

To match public service buildings with landscapes and neighboring environments, high-transparency glass wall design is often introduced. Nonetheless, located in the subtropics, the high temperatures in summer influence the comfort of indoor environments in Taiwan. Although glass surfaces are specially treated to enhance the proportion of reflection and diffusion and reduce the transmission material, the indoor temperature is still high. Whenever the outdoor temperature rises in the summer, the external heat enters indoors through conduction, radiation, and convection, thus, increasing the temperature of the indoor environment [1,2]. In order to maintain the basic indoor living comfort, air conditioning systems have become essential equipment in such public spheres. Moreover, the power consumption of airconditioners increases with rising outdoor temperature; in particular, this increases the energy consumption in large spheres offering public services. The call for green buildings offering energy saving, carbon reduction and environmental protection is increasing globally in recent years [3]. However, this kind of practice presents difficulties because of the physical factors of global warming in thermal environment and indoor comfort, such as heat radiation, air movement, and temperature \& humidity distribution. These four factors must be properly controlled to achieve better environments and comfort [4]-[6].
Taking the Kouhu Visitor Center in the Southwest Coast National Scenic Area as the experimental target, "numerical simulation" and "field data" are applied to collect data and carry out mutual verification at the same time. Under simulated weather conditions, the duration of sunshine, temperature distribution, heat balance, and space comfort between the measurement and the numerical simulation are mutually compared to analyze the effects of building envelope materials, with distinct thermal resistance and thermal conductivity coefficients, and sunshine direction \& duration. The effect of indoor venue comfort on visitors' recreational behaviors is examined. The findings can serve as a reference for relevant maintenance and management sectors.

\section{Material and method}

\subsection{Research area}

Kouhu Visitor Center in the Southwest Coast National Scenic Area Administration of the Tourism Bureau, M.O.T.C. was selected as the experimental area. The building plan features landscape architecture, and two irregular masses interlocking the image of a bird spreading its wings before flight. The building body is mainly built by reinforced concrete and large glass walls matched with wooden gratings and the roof is designed as a slope extending from a scenic green roof trail to the ground. In addition to the shadow of the green roof, there 
are no building or tree shelters around the building. Although the glass wall is designed with wooden gratings, there are no large window openings (Fig. 1). The indoor space of the building is mainly divided into three zones (A, B, C), as shown in Fig. 2.
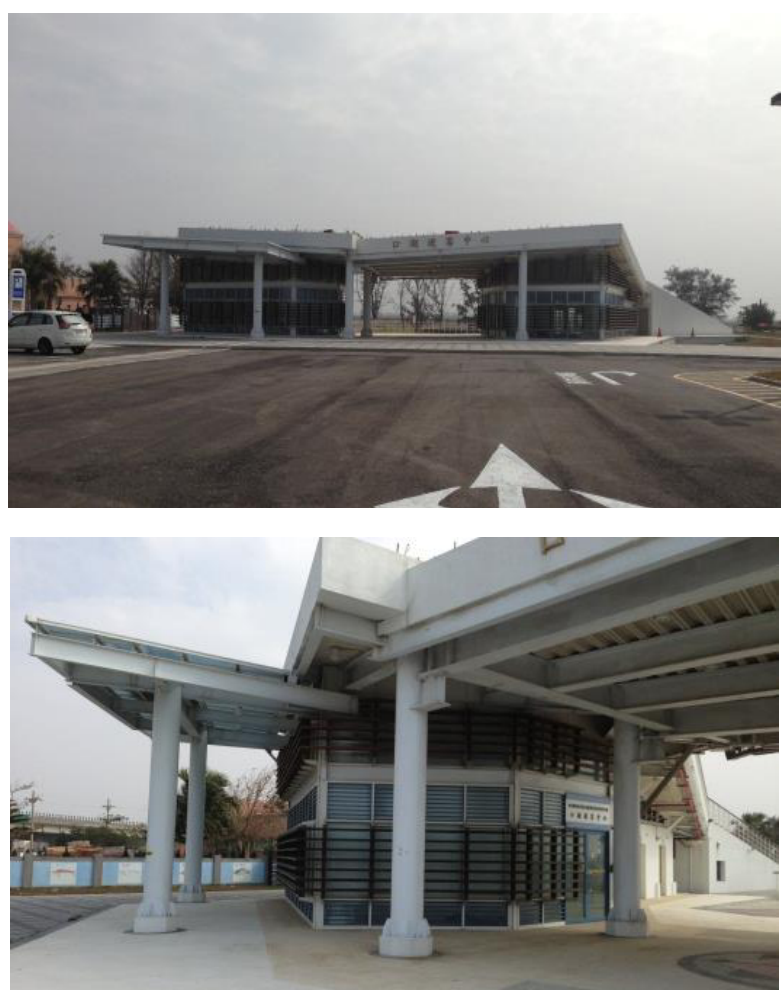

Figure 1. Building appearance of the Kouhu Visitor Center in the Southwest Coast National Scenic Area.

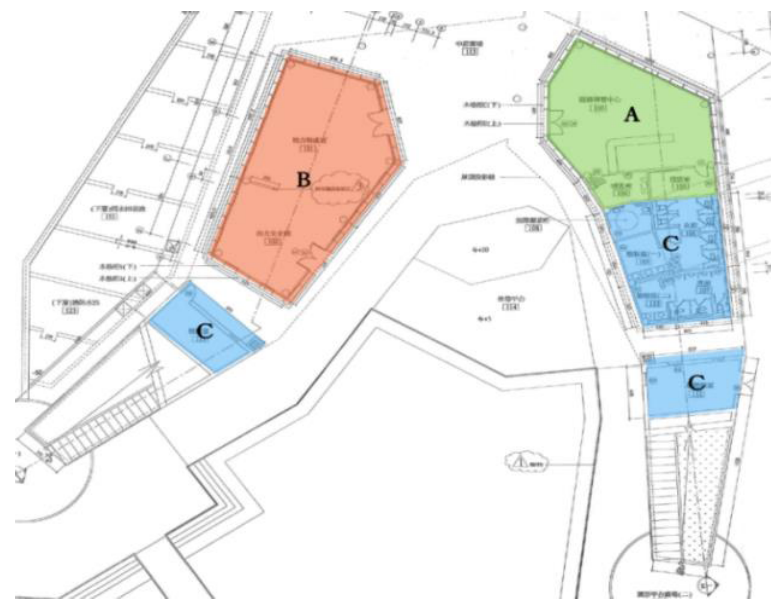

Figure 2. Indoor space zones of the building.

\subsection{In situ meteorology}

The meteorological data reveal high temperatures and humidity. The climatic zone is located $20 \mathrm{~km}$ north of the Tropic of Cancer, in the Subtropics. The mean annual temperature is about $22.6^{\circ} \mathrm{C}$, with up to 220 days with a mean temperature above $22^{\circ} \mathrm{C}$ per year, and the changes in four seasons are not apparent. In regard to the temperature change cycle, the temperature gradually rises up to $20^{\circ} \mathrm{C}$ in March, and the highest temperatures in a year occur from June to September. The highest temperature in summer reaches $28^{\circ} \mathrm{C}$ and even higher.
The temperature in October and November gradually drops, and the lowest temperature appears between December and February, when the lowest winter temperature drops down below $20^{\circ} \mathrm{C}$. The mean relative humidity is around $80 \%-90 \%$.

\subsection{Numerical simulation}

Ecotect, the environment numerical simulation software [7], is used in this study for the numerical modeling based on the completed drawing size and boundary conditions of the numerical simulation, including the meteorological data (organized from the Data Bank for Atmospheric \& Hydrologic Research and Yunlin Weather Station of the Central Weather Bureau), the elevation coordinates $(+4 \mathrm{~m}$ above sea level), and the geographic location (East longitude $120.1877^{\circ}$ and North latitude $23.5460^{\circ}$ ).

\subsection{Field data}

An infrared thermal imager (a contactless and highsensitivity infrared thermal imager with the measuring range of $-20^{\circ} \mathrm{C} \sim 250^{\circ} \mathrm{C}$ ) is used for irradiating the building surface and measuring the surface temperature to further deduce the actual temperature change and distribution of the building envelope. Meanwhile, a multi-functional thermometer was placed inside the visitor center for the continuous monitoring from February - April, 2013. Under the conditions of natural ventilation without use of the air-conditioning system, the long-term observed data were recorded by monitoring the temperature, humidity, and solar radiation.

\section{Result and discussion}

According to the analyses with an infrared thermal imager and numerical simulation, the hourly, daily temperatures in the visitor center are shown in Fig. 3 and Fig. 4. The outdoor temperature in zones $\mathrm{A}, \mathrm{B}$, and $\mathrm{C}$ obviously rises after 6 a.m. because of the duration of sunshine. The highest temperature appears at 11 a.m., and the temperature becomes stable after 6 p.m. The obvious temperature difference between day and night corresponds the findings of previous works [8]. As seen in Fig. 3, the building materials in zones A and B show higher thermal resistance; although the temperature rises slowly, the high thermal resistance causes higher indoor temperatures compared to the outdoor temperature during the day. In this case, the indoor temperature, under the same external climate conditions, apparently changes with distinct building orientation, window design, and building materials (zone $\mathrm{B}$ reveals higher indoor temperature).

According to the calculation with Ecotect [9], the hourly heat analysis is used for simulating the thermal environment in this study. Moreover, it is assumed that the internal temperature of any building approaches the local outdoor temperature and generates delay or restraint caused by the heat capacity as well as the shelter of the building body. As a result, the indoor temperature 
changes are similar to the changes of the outdoor temperature. As a result, when the total heat loss is equal to the total heat gain, the indoor temperature is stable. Meanwhile, the heat gain and loss results based on the
HVAV load, structural conduction, temperature (SOLAIR), solar radiation heat, natural ventilation, internal personnel and equipment, and inter-zonal are also analyzed.

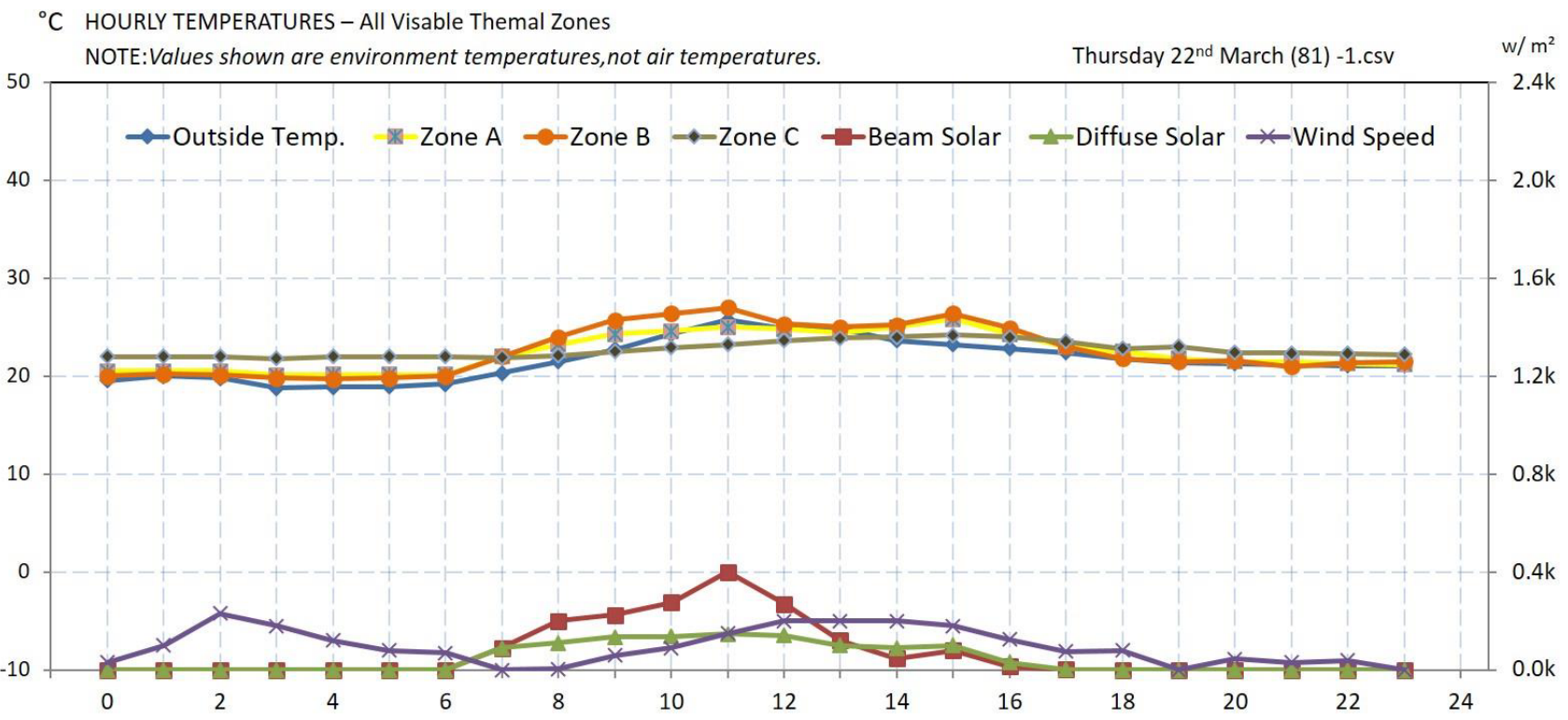

Figure 3. Indoor/outdoor hourly temperature.

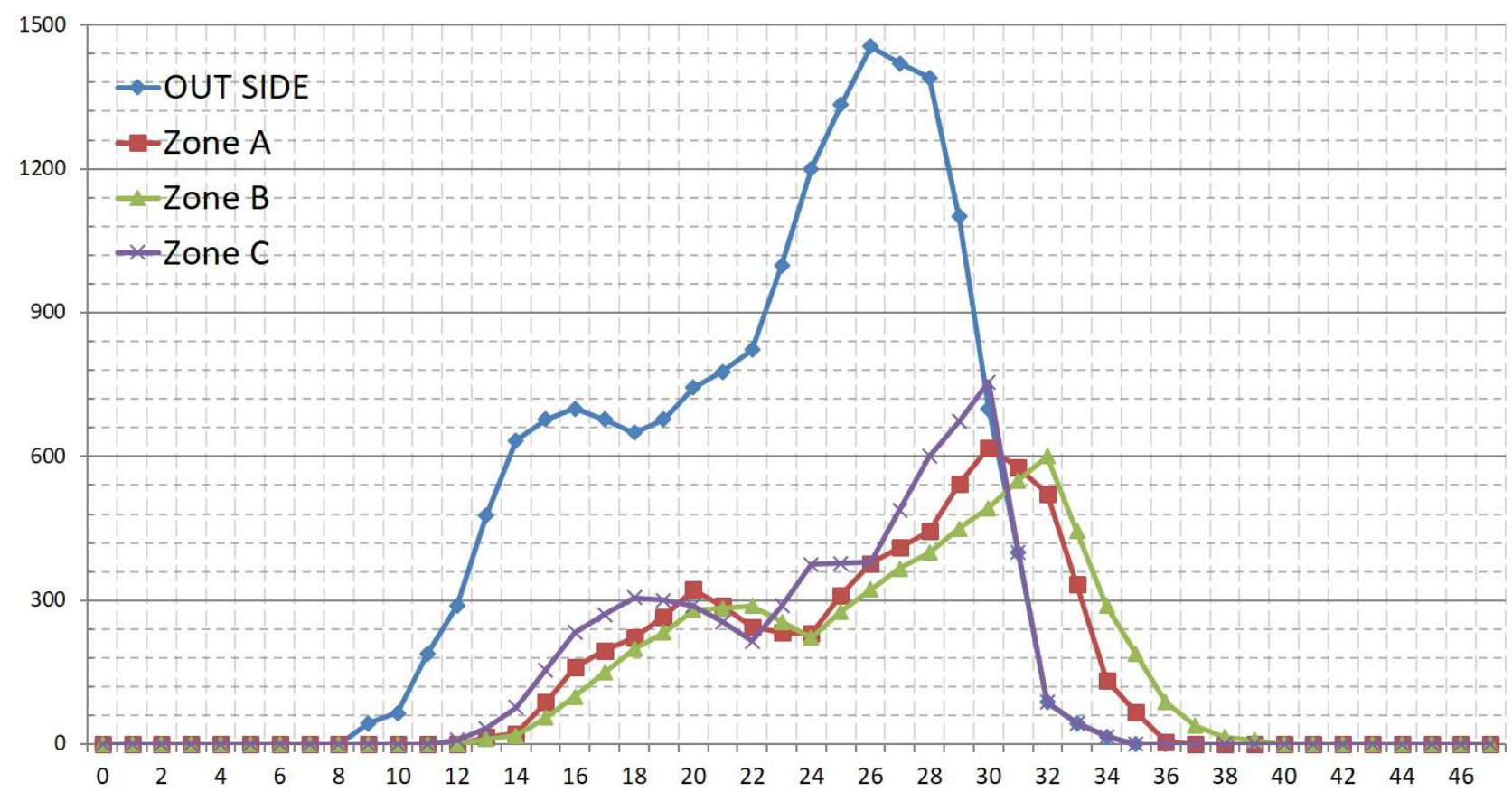

Figure 4. Outdoor and research area temperature distribution.

The calculation shows that the solar radiation accounts for the majority of heat gain in the summer, about $31.0 \%$, followed by internal personnel and equipment, $21.4 \%$, building structural conduction, $21.0 \%$, and comprehensive temperature heat, $16.9 \%$. Ventilation and inter-zonal heat gain and loss are the least, at about $8.0 \%$ and $1.8 \%$, respectively. The duration of sunshine is longer and the mean temperature is high in summer. The building body is radiated by the sun for a long time and the heat from the sun conducts through the structure as the building body absorbs large amounts of heat; the heat is also conducted to the building through the structure; and, the radiation heat and the outdoor heat blown in by the wind enter indoors through doors and windows, adding to the heat from indoor personnel and equipment.

Regarding the three zones in the indoor space, numerical simulation is used for accumulating the number of annual temperature hours. People perceive more serious discomfort in zones $\mathrm{A}$ and $\mathrm{B}$ than in zone $\mathrm{C}$. Discomfort in zone B appears to be even higher; visitors 
explained that they felt uncomfortable in zone B, and rarely expressed that they felt chilly in the building. Apparently, the indoor temperature of the visitor center is high in summer. As a result, visitors perceived higher discomfort.

\section{Conclusions}

Taiwan, with its hot-humid climate, was selected as the research subject. Aiming at the open building environment of a visitor center, the envelope surface temperature, physical environment measurements, and numerical simulation are analyzed. The research result reveals that sunshine orientation affects the change of indoor temperature. Moreover, longer duration of sunshine continuously increases the temperature, and the heat is trapped indoors and slowly distributed when the thermal resistance is high and the thermal conductivity coefficient is low, resulting in sultriness. The heat gain in the visitor center throughout the year results from solar radiation, $31 \%$, personnel and equipment, $21.4 \%$, and structural conduction, $21 \%$. Under the same weather conditions, the shadow caused by the building orientation affects the indoor temperature. Various data reveal that the indoor temperature in zone B is obviously higher with greater discomfort than in other zones in summer. However, the temperature and discomfort are lower in this zone in the winter. These results could serve as a reference for future improvement or the design of other buildings.

\section{References}

1. R.L. Hwang, M.J. Cheng, The Open Construction and Building Technology Journal 1 (2007).

2. C.A. Roulet, Journal of the Energy and Environment 33, 3 (2000).

3. Construction \& Planning Agency, Building EnergySaving Design Specifications, Ministry of the Interior, Taiwan, (2011).

4. ASHRAE, ANSI: Standard 55-2004, Thermal Environmental Conditions for Human Occupancy, Atlanta: American Society of Heating (Refrigerating, and Air-conditioning Engineers. Inc., USA, 2004).

5. C. Bouden, Journal of the Renewable Energy 32, 1 (2007).

6. Y. Etzion, E. Erell, Building \& Environment 35, 5 (2000).

7. Ecotect, Ecotect Tutorial. Ver. 5.20, Joondalup, WA, Square One research Pty Ltd., (2003).

8. T.C. Liang, W.C. Hsu, Journal of National Huwei University of Science \& Technology 32, 1 (2014).

9. G. Mihalakakou, A. Ferrante, Energy Conversion \& Management 41 (2000). 